San Antonio Review • San Antonio Review (Volume IV | Fall 2020)

\title{
The Question White Parents Should Be Asking
}

Margaret A. Hagerman ${ }^{1}$

${ }^{1}$ Mississippi State University

Published on: Aug 07, 2020

DOI: $10.21428 / 9 b 43 c d 98 . d b 33062 d$

License: Creative Commons Attribution 4.0 International License(CC-BY 4.0). 
This past summer, white parents across the United States repeatedly asked the same question: "How should I talk to my white child about race?" In response, parenting magazine writers, bloggers and newspaper columnists framed article after $\underline{\text { article }}$ as responses to this question. Again and again, social

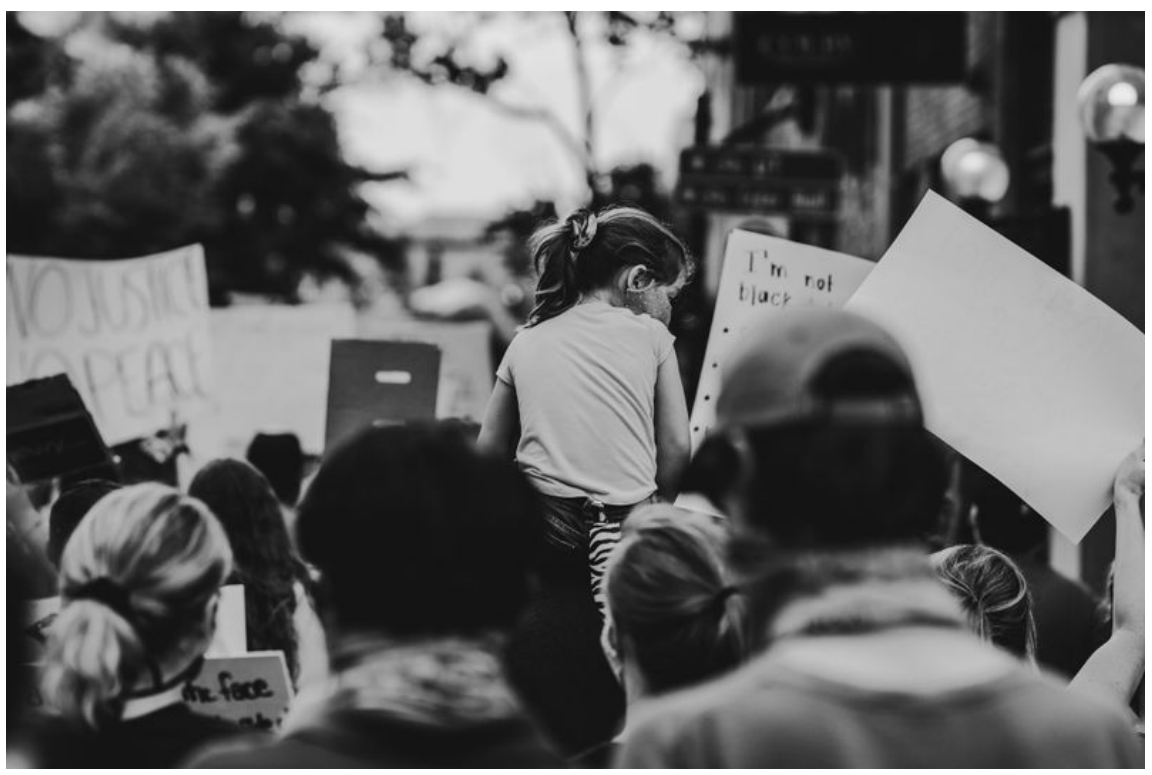

"Black Lives Matter protest in Tennessee," Photo by Zoe VandeWater on Unsplash scientists who study families were bombarded by mainstream media requests to respond to this same query: "What advice do you have for white parents on how they can talk to their white kid about racism in America?"

The reality is that the question about how to talk about race consistently emerges in the aftermath of racial violence in America. In fact, I keep a collection of these essays, articles, and blog posts to use when I teach my college students about how kids learn about race. I have a whole PowerPoint slide with headlines from my collection that I use when I share my research on white families with public audiences. The reason I use this collection is to demonstrate the pattern I see of an overwhelming focus on talk rather than action.

I am a sociologist who studies how white kids learn about race, racism, racial inequality and privilege in the context of their ordinary, everyday lives. As detailed in my book, White Kids: Growing_Up with Privilege in a Racially Divided America, I spent two years with 36 affluent, white kids aged 10-13 and their families, listening to their ideas and observing them as they encountered their social worlds. I went to country clubs and Boy Scout troop Laser Tag events, birthday parties and soccer games. I helped kids with homework, drove them to piano lessons, and ate dinner with their families. 
I found that the well-intentioned and popular question of "how to talk to white kids about race" is not the question white parents should be asking-or at least not the only one. This is because the white kids in my study did not learn about race primarily through conversations with their parents. Rather, the kids' ideas came largely from the observations they made about the social environment around them-an environment their parents strategically designed for them using available resources. And this was true whether their parents talked with them about race or not.

\section{Social Environment and Racial Learning}

In a segregated and racially unequal society, racial patterns do not go unnoticed by children. Much like similar research conducted with Black children, the white kids in my study developed understandings about race through their observations of how things are organized around them. What kind of people live in the "nice" houses? What neighborhoods do parents lock the car doors while driving through? What kind of kids get in trouble the most at school? The children in my study interpreted messages like these as they interacted with teachers, peers, coaches, strangers, and their parents' friends in a variety of social settings. Their ideas about race were thus shaped in large part by what I call the "racial context of their childhood."

For example, in my study, 12-year old Edward's family did not talk openly about race. However, one afternoon as we waited in a McDonald's drive-thru, he observed a group of Black kids playing and laughing in the snow, just like he and his friends did all the time. Edward asked me, "This neighborhood isn't really all that good, is it?" Despite not talking openly about race at home, and despite telling me only a few weeks prior that "race doesn't matter anymore," Edward had clearly internalized the idea that Black people and neighborhoods are bad.

I also found that even if critical conversations about race happened in the home, the kids in my study still interpreted many messages about race outside the home, too. And often, the environment outside the home was shaped by choices their parents made about where to live, schools they would attend, which friends to have and so on. As scholars like Karolyn Tyson, $\underline{\text { Amanda Lewis, }}$ and Carla Shedd each illustrate, kids learn ideas about race through interpreting patterns they see in their everyday lives, including at schools and in their local communities.

In the case of the affluent, white kids in my research, this included learning what it means to experience the world from a position of privilege. For instance, 11-year-old Aaron attended a predominantly white private school where he was told by his parents 
and teachers that he attended this school because he was "special," "better" and "smarter" than the kids at the local public school. It was commonly held knowledge that in this particular community, the vast majority of the Black and brown kids attended public school.

As a result of this pattern of school segregation, Aaron developed ideas about what kinds of kids are "special" and "more deserving" than others-and he learned where he is situated in social hierarchies. Ironically, Aaron was able to talk in sophisticated ways about institutional racism because of the conversations in his home. We talked at great length, for instance, about the racial wealth gap. Nevertheless, the broader context in which Aaron lived, including the schools his parents chose for him, played a powerful role in convincing Aaron that he was superior to "other" kids at the public school. And this is what he told me he believed to be true about himself: he believed that he would go to a school like Harvard someday and become a leader, because that is what people like him do.

\section{Peers and Media}

Over the course of my research, it became very clear to me that many of these white kids had a lot of questions about race-and found answers to these questions by talking to other kids. Sometimes they would tell me about things they learned about race from watching movies, television program, and even the local news.

One afternoon, I observed Carly, age 12, her younger sister, and a friend discuss musician Rihanna's racial identity. The girls disagreed about her racial classification. One girl thought Rihanna was Black— "or at least a mix" —-while another girl argued that Rihanna was white but wearing a lot of bronzer makeup. The girls discussed rubbing bronzer makeup on their own white arms to see if they could get their skin to look like Rihanna's. Carly told the others that she really wanted Rihanna to be "white with bronzer like me" rather than Black.

Another afternoon I watched two boys debate whether Black athletes have an extra muscle in their legs that allows them to jump higher and run faster. I listened as the boys argued back and forth about this while eating string cheese. In the end, they wrongly concluded that since race is "biological," it must be true that these fundamental anatomical differences exist.

Overall, although these kids had questions about race, most did not talk with their parents about the topic. Some told me they didn't think their parents would listen to them anyway. One child even told me, "My mom just hates talking about that stuff." 


\section{Raising a "good" white kid}

Many well-meaning white parents tell me they do not want to raise "a racist kid." They say they want to raise a "good" white kid. But parents who see the world this way accept a logic that there is such a thing as a "good" white kid who is not racist and a "bad" white kid who is.

Of course, there are children who use racist insults at the interpersonal level, like chanting “Build the wall!" in the faces of their Latinx peers or posting racist content on TikTok. There are even examples of young white people who join racist white nationalist groups. These acts must be addressed.

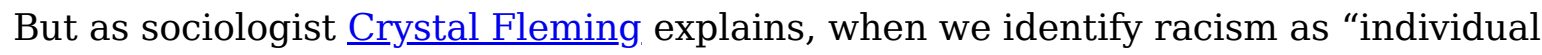
attitudes, prejudice, or the actions of a few extremists" alone, we collectively deny and miss the reality that white supremacy is a "system of power" - it is about far more than an individual kid with racist ideas.

Focusing on whether a kid is racist or not ignores the reality that racism is deeply_ embedded in our society's institutions and has been for centuries. It ignores the ways that we are all actors in a racialized social system, or a society organized fundamentally by the socially constructed concept of race.

\section{Collective Decisions of White Parents}

Thinking about racism solely in individualist terms also denies the fact that white parents often act in collective ways to maintain structural arrangements that work well for them. This can be seen historically in the formation of segregationist academies throughout the U.S. South, an effort led by white parents, or in white parents' opposition to desegregation efforts in Northern cities.

But this can also be seen today. When the school district in my study considered redistributing resources to support students at the public high school who were struggling academically, and who were disproportionately Black, white parents banded together, and used various forms of capital to ensure that their children's extracurricular opportunities remained intact. "We chose this school because of these opportunities, and we expect them to be available for our kids," was the viewpoint shared with me.

These were the same parents who also told me that they believed in racial justice. 
When white parents use what Amanda Lewis and John Diamond refer to as the "symbolic capital of whiteness" to ensure that the school practices that serve their children well do not change, they engage in what sociologist Charles Tilly. defines as "opportunity hoarding." Evidence of opportunity hoarding can be seen in micro-level interactional processes between parents and teachers, in practices of how kids get sorted into Gifted and Talented programs, and through racialized tracking_practices in general. These practices can also be seen when parents like those in my study use their social networks to get their kid a coveted summer internship or moved into the "best" math class.

Although parents do not view their choices as attempts to sabotage others or reinforce inequality, their actions contribute to these consequences nonetheless. And when parents engage in these behaviors in patterned ways, their individual actions become collective and ultimately reproduce the unequal racial status quo. As Lewis and Diamond powerfully write, these white parents are "not just advocating for their own children. They are also advocating for the maintenance of the structures of inequality that facilitate their advantage."

Of course, it does not have to be this way, as Brittany Murray et al. illustrate in their recent research and as organizations like We Stories and Integrated Schools demonstrate in practice. Solidarity can instead be built across all parents in a school or community so that everyone is invested in everyone else-but that requires a different way of thinking about what it means to advocate for children than what I commonly observed in my research.

\section{Actions Speak Louder Than Words}

Some people believe that the recent uprising in response to the police killings of George Floyd and Breonna Taylor will become a racially transformative moment in American history. Perhaps this is will be the case. Certainly, we have seen some meaningful changes this summer, like reforming the police force or removing_police from schools, an action for which Black youth activists and scholars of the school-toprison pipeline have long advocated.

But will white parents who attended Black Lives Matters protest marches back in June with their children do more than talk to their kids about racism in the months ahead?

If living in a future society with deep racial divides and continued racist violence is not what we want for the future, white, affluent parents need to do more than talk to their 
kids about racism. White parents need to ask different questions that lead to different behaviors.

Based on my research, the question white parents should be asking is, "How can I align what I do with what I say I value?"

Certainly, white parents have a role to play in changing the institutional drivers of inequality. And often, race and class privileged people like those in my research are positioned such that they themselves can powerfully influence and shape institutions directly. For example, as Jessica Calarco illustrates, due to current school funding practices, U.S. schools are "privilege-dependent organizations." These institutions depend on and cater to affluent white families, selectively enforcing rules about homework and giving those kids more leeway. What if privileged parents used their position to disrupt these unfair practices rather than participating in them?

Whether or not white parents are influential members of their communities, they can support policies, practices and laws designed to create big, broad changes. They can vote for politicians who will write new laws and enact policies that support the redistribution of material resources in society across the board. For example, they can support changes to how public schools are funded.

White parents can also think more about the racial context of their children's lives. They can think more carefully about the messages they are sending their kids when they opt to live in an exclusively white neighborhood, or when they volunteer in or travel to communities different from their own. And perhaps they can make different choices in the future. White parents can think more deliberately about the kinds of social settings they enter and make different choices about which soccer teams they select, what kind of media they consume, or how they engage with their peers. They can model what it looks like to stand up to racism in private white spaces, like when an extended relative makes a racist comment at a family dinner.

\section{Prioritizing the Common Good}

But perhaps most important, white parents can also make different collective decisions on a regular, everyday basis-decisions that bring their actions in line with what they value. For example, white parents can make the decision to support public schools and integration efforts through the choices they make about neighborhoods and schools. White parents can reject practices of school discipline and tracking that are shown to perpetuate racial inequality. They can advocate for more material resources channeled to children from marginalized groups, even if that undermines the advantage their own 
kids might otherwise have had. White parents can learn to listen and partner with Black and brown parents rather than dominating spaces like PTA meeting . These are just some examples of what white parents can do differently.

As a friend put it to me recently, white parents do not need to give up the idea that their child is special to them. They just need to accept the idea that other children deserve just as many opportunities to grow, to learn and to flourish as their own kids.

Talking to white children about racism is an important start. But white parents cannot simply change what they say - they must also change what they do. If white parents really want to teach their children that Black Lives Matter, they must make different decisions that prioritize the common good.

Margaret A. Hagerman, Ph.D. is an Associate Professor of Sociology at Mississippi State University. She is the author of White Kids: Growing_Up with Privilege in a Racially_Divided America (NYU Press, 2018). 